Provided for non-commercial research and education use. Not for reproduction, distribution or commercial use.

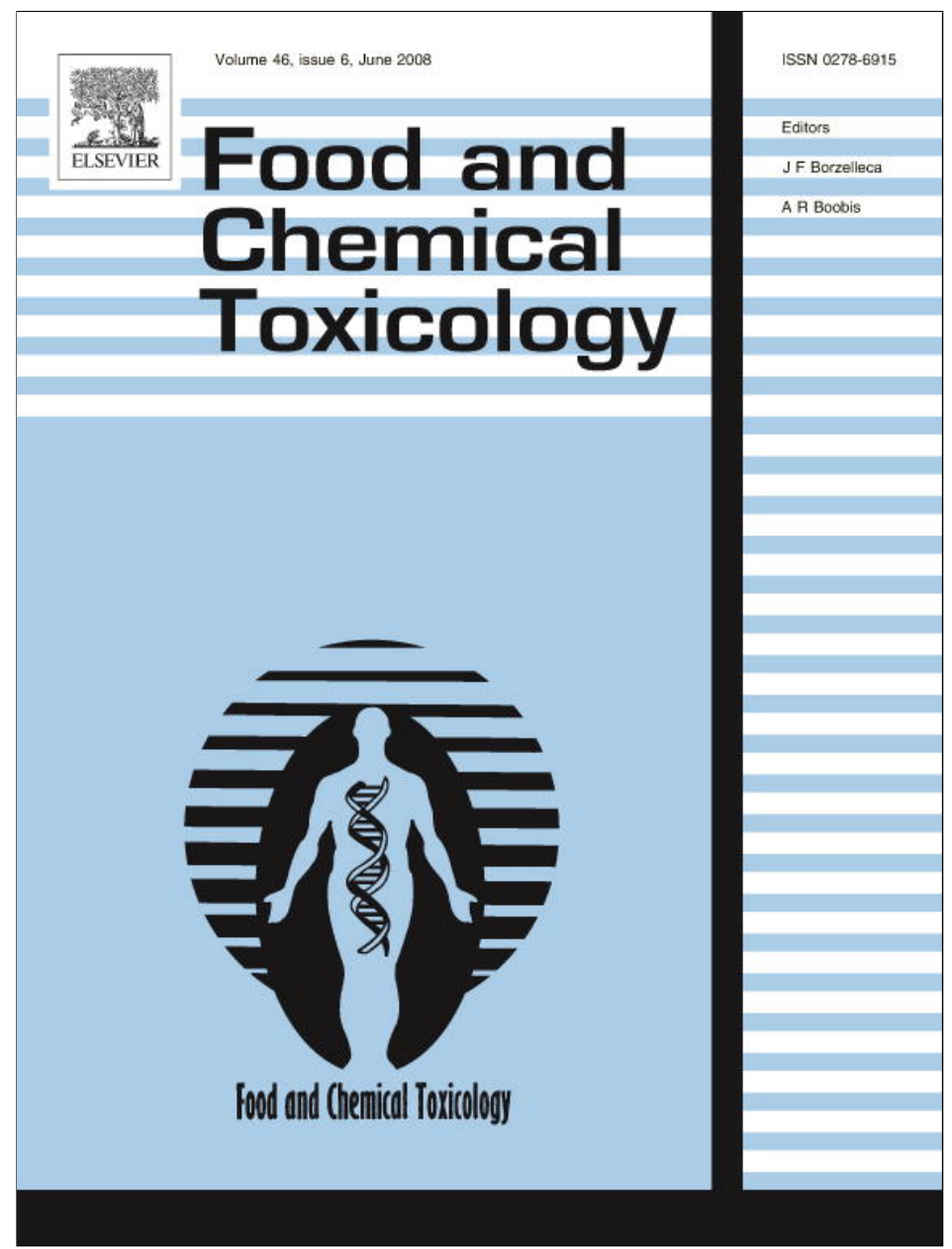

This article appeared in a journal published by Elsevier. The attached copy is furnished to the author for internal non-commercial research and education use, including for instruction at the authors institution and sharing with colleagues.

Other uses, including reproduction and distribution, or selling or licensing copies, or posting to personal, institutional or third party websites are prohibited.

In most cases authors are permitted to post their version of the article (e.g. in Word or Tex form) to their personal website or institutional repository. Authors requiring further information regarding Elsevier's archiving and manuscript policies are encouraged to visit:

http://www.elsevier.com/copyright 


\title{
Bioactive properties and chemical composition of six walnut (Juglans regia L.) cultivars
}

\author{
José Alberto Pereira*, Ivo Oliveira, Anabela Sousa, Isabel C.F.R. Ferreira, \\ Albino Bento, Letícia Estevinho \\ CIMO/Escola Superior Agrária, Instituto Politécnico de Bragança, Campus Sta Apolónia, Apartado 1 172, 5301-855 Bragança, Portugal
}

Received 24 January 2008; accepted 1 February 2008

\begin{abstract}
The chemical composition, antioxidant potential and antimicrobial activity were studied in six walnuts (Juglans regia L.) cultivars (cv. Franquette, Lara, Marbot, Mayette, Mellanaise and Parisienne) produced in Portugal. Concerning their chemical composition the main constituent of fruits was fat ranging from $78.83 \%$ to $82.14 \%$, being the nutritional value around $720 \mathrm{kcal}$ per $100 \mathrm{~g}$ of fruits. Linoleic acid was the major fatty acid reaching the maximum value of $60.30 \%$ ( $c v$. Lara) followed by oleic, linolenic and palmitic acids. The aqueous extracts of walnut cultivars were investigated by the reducing power assay, the scavenging effect on DPPH (2,2-diphenyl-1-picrylhydrazyl) radicals and $\beta$-carotene linoleate model system. All the walnut extracts exhibited antioxidant capacity in a concentration-dependent manner being the lowest $\mathrm{EC}_{50}$ values obtained with extracts of $c v$. Parisienne. Their antimicrobial capacity was also checked against gram positive (Bacillus cereus, Bacillus subtilis, Staphylococcus aureus) and gram negative bacteria (Pseudomonas aeruginosa, Escherichia coli, Klebsiella pneumoniae) and fungi (Candida albicans, Cryptococcus neoformans), revealing activity against the different tested microorganisms.
\end{abstract}

(C) 2008 Elsevier Ltd. All rights reserved.

Keywords: Juglans regia L.; Fatty acids; Nutritional value; Antioxidant properties; Antimicrobial activity

\section{Introduction}

Nuts are important components of the Mediterranean diet. Walnuts (Juglans regia L.) are widely distributed all over the world, and in Portugal, these species are common along the country. These fruits are receiving increasing interest as a healthy foodstuff because their regular consumption has been reported to decrease the risk of coronary heart disease (Blomhoff et al., 2006; Davis et al., 2007). The health benefits of walnuts are usually attributed to their chemical composition. Walnuts are a good source of essential fatty acids and tocopherols (Amaral et al., 2003, 2005). Linoleic acid is the major fatty acid, followed by oleic, linolenic, palmitic, and stearic (Amaral et al., 2003; Ruggeri et al., 1998; Savage et al., 1999); its high con-

\footnotetext{
${ }^{*}$ Corresponding author. Tel.: +351 273 303277; fax: +351 273325405.

E-mail address: jpereira@ipb.pt (J.A. Pereira).
}

tent of PUFA has been suggested to reduce the risk of heart disease by decreasing total and LDL-cholesterol and increasing HDL-cholesterol (Davis et al., 2007; Tapsell et al., 2004). In addition, walnuts have other components that may be beneficial for health including plant protein, dietary fibber, melatonin (Reiter et al., 2005), plant sterols (Amaral et al., 2003), folate, tannins, and polyphenols (Anderson et al., 2001; Li et al., 2006). The chemical composition, namely the oil content and the fatty acid and tocopherols have been found to vary significantly among different walnut cultivars and environmental condition (Amaral et al., 2005).

Foods of plant origin, such as fruits and vegetables and whole grain products have been suggested as a natural source for antioxidants. Antioxidants can play an important role in disease prevention and health maintenance. Plant-derived products can be used either as a source of antioxidants in industry or for medicinal purposes 
(Ramadan and Moersel, 2006). The antioxidant effect showed by these products proceeds from phenolic compounds and phytochemicals, which protect from harmful effects of free radicals (Fukuda et al., 2003; Kornsteiner et al., 2006). Walnut possess a high content of $\alpha$-tocopherol, (Amaral et al., 2005) a vitamin E family compound, which has antioxidant activity, mainly in the prevention of lipid oxidation process (Amaral et al., 2005; Koksak et al., 2006).

Plant-derived products can also be used as antimicrobial agents, with phenolics and polyphenolic having major interest (Cowan, 1999). The increased resistance to antibiotics and the problems presented by antimicrobial agents added in food (resistance, mutagenesis and carcinogenesis effects, for example) and public's pressure on the food industry to avoid chemical preservatives are the main factors justifying the search and development of new antimicrobial agents, especially those of natural origin (Rauha et al., 2000; Puupponen-Pimiä et al., 2001; Proestos et al., 2005). Antimicrobial activity of phenols as already been reported (Fernández et al., 1996; Oliveira et al., 2007; Pereira et al., 2006, 2007; Proestos et al., 2005; Sousa et al., 2006).

In previous works the chemical composition of walnut fruits produced in Portugal was presented (Amaral et al., 2003, 2004). Recently, our research group evaluated also the antioxidant activity and antimicrobial potential of walnut leaves (Pereira et al., 2007). Nevertheless, information about aqueous walnut kernel extracts antioxidant activity is not extended and is inexistent concerning their antimicrobial activity.

In the present work, six walnut cultivars ( $c v$. Franquette, Lara, Marbot, Mayette, Mellanaise and Parisienne) grown in Portugal, were characterized in respect to their chemical composition, antioxidant potential and antimicrobial activity. The samples were analyzed for proximate constituents (moisture, fat, crude protein, ash), nutritional value and fatty acids profile by GC/FID. Antioxidant potential was accessed by the reducing power assay, the scavenging effect on DPPH (2,2-diphenyl-1-picrylhydrazyl) radicals and $\beta$ carotene linoleate model system. We also demonstrate for the first time, as far as we know, the antimicrobial activity of walnut extracts studying their antimicrobial capacity against gram positive (Bacillus cereus, Bacillus subtilis, Staphylococcus aureus) and gram negative bacteria (Pseudomonas aeruginosa, Escherichia coli, Klebsiella pneumoniae), and fungi (Candida albicans, Cryptococcus neoformans).

\section{Materials and methods}

\subsection{Samples}

Walnut fruits were obtained from six J. regia L. cultivars (Franquette, Lara, Marbot, Mayette, Mellanaise and Parisienne), and were collected on September 2006 in Bragança, northeast of Portugal $\left(41^{\circ} 47^{\prime} 47.50918^{\prime \prime} \mathrm{N}\right.$, $\left.6^{\circ} 46^{\prime} 5.71990^{\prime \prime} \mathrm{W}, 744.341 \mathrm{~m}\right)$. The orchard has a planting density of $3.5 \times 7 \mathrm{~m}$. The trees are ten years old, being pruned when necessary. No phytosanitary treatments were applied. The fruits, $\approx 2 \mathrm{~kg}$ per cultivar, were handpicked from the soil, dried in a stove (Memmert Schwabach 854,
1994) at $30^{\circ} \mathrm{C}$, in the dark, for five days. The fruits were put in plastic bags and frozen to $-20^{\circ} \mathrm{C}$ until the analyses.

\subsection{Samples preparation}

Before each kind of analysis (chemical, antioxidant and antimicrobial) the walnuts were manually cracked and shelled, and then chopped in an appliance mill (model A327R1, Moulinex, Spain). For fatty acid analysis, crude oil was obtained from finely chopped nuts (ca. $15 \mathrm{~g}$ ) extracted with light petroleum ether (b.p. $40-60^{\circ} \mathrm{C}$ ) in a Soxhlet apparatus; the remaining solvent was removed by vacuum distillation.

\subsection{Chemical analysis}

Analyses of moisture, total fat, ash, and protein contents were carried out in duplicate according to AOAC Official Methods (AOAC, 1995). Moisture was determined at $100\left( \pm 2{ }^{\circ} \mathrm{C}\right)(5 \mathrm{~g}$ test sample $)$ in a stove until constant weight. Total fat was determined by extracting a known weight of sample $(5 \mathrm{~g})$ with petroleum ether, using a Soxhlet apparatus; the ash content was determined by incineration at $600 \pm 15^{\circ} \mathrm{C}$. The crude protein content $(N \times 4.38)$ of the samples was estimated by the macroKjeldahl method. Carbohydrate content was estimated by difference of the other components using the following formula: carbohydrate content $=100 \%-(\%$ moisture + protein $+\%$ fat $+\%$ ash $) . \quad$ Energy was expressed as kilocalories, using the factors mentioned in the Portuguese Legislation (Decreto-Lei no. 167/2004): Energy (kcal) $=4 \times(\mathrm{g}$ protein $+\mathrm{g}$ carbohydrate $)+9 \times(\mathrm{g}$ lipid $)$.

\subsection{Fatty acid composition}

Fatty acids were determined by gas chromatography with flame ionization detection (GC-FID) capillary column based on the following transesterification procedure: fatty acids were methylated with $5 \mathrm{~mL}$ of methanol:sulphuric acid:toluene 2:1:1 (v/v), during at least $12 \mathrm{~h}$ in a bath at $50{ }^{\circ} \mathrm{C}$ and $160 \mathrm{rpm}$; then the $5 \mathrm{~mL}$ of deionised water were added, to obtain phase separation; the FAME were recovered with $5 \mathrm{~mL}$ of diethyl ether by shaking in a vortex, and the upper phase was passed through a micro-column of sodium sulphate anhydrous, in order to eliminate the water; the sample was recovered in a vial with Teflon, and before injection the sample was filtered with $0.2 \mu \mathrm{m}$ nylon filter from Milipore. The fatty acid profile was analyzed with a DAN1 model GC 1000 instrument equipped with a split/splitless injector, a flame ionization detector (FID) and a Macherey-Nagel column $(30 \mathrm{~m} \times 0.32 \mathrm{~mm} \mathrm{ID} \times 0.25 \mu \mathrm{m} \mathrm{df})$. The oven temperature program was as follows: the initial temperature of the column was $50{ }^{\circ} \mathrm{C}$, held for $2 \mathrm{~min}$, then a $10^{\circ} \mathrm{C} / \mathrm{min}$ ramp to $240{ }^{\circ} \mathrm{C}$ and held for $11 \mathrm{~min}$. The carrier gas (hydrogen) flow-rate was $4.0 \mathrm{~mL} / \mathrm{min}$ (0.61 bar), measured at $50^{\circ} \mathrm{C}$. Split injection $(1: 40)$ was carried out at $250{ }^{\circ} \mathrm{C}$. For each analysis $1 \mu \mathrm{L}$ of the sample was injected in GC. The results were recorded and processed using CSW 1.7 software (DataApex 1.7) and expressed in relative percentage of each fatty acid, calculated by internal normalization of the chromatographic peak area. Fatty acids were identified by comparing the relative retention times of FAMEs peaks from samples with standards.

\subsection{Extract preparation}

For each cultivar, three powdered sub samples ( $\sim 5 \mathrm{~g} ; 20$ mesh) were extracted with $250 \mathrm{~mL}$ of boiling water for $45 \mathrm{~min}$ and filtered through Whatman no. 4 paper. The aqueous extracts were frozen, lyophilized and redissolved in water at concentrations of $100 \mathrm{mg} / \mathrm{mL}$ and $10 \mathrm{mg} / \mathrm{mL}$ for antimicrobial and antioxidant activities assays, respectively.

\subsection{Determination of total phenol content}

Phenolic compounds concentration in the obtained extracts was estimated by a colorimetric assay based on procedures described by Singleton 
and Rossi (1965) with some modifications. Briefly, $1 \mathrm{~mL}$ of sample was mixed with $1 \mathrm{~mL}$ of Folin and Ciocalteu's phenol reagent. After 3 min, $1 \mathrm{~mL}$ of saturated sodium carbonate solution was added to the mixture and adjusted to $10 \mathrm{~mL}$ with distilled water. The reaction was kept in the dark for $90 \mathrm{~min}$, after which the absorbance was read at $725 \mathrm{~nm}$ (Analytik Jena 200-2004 spectrophotometer). Gallic acid was used for constructing the standard curve $(0.01-0.4 \mathrm{mM})$. The results are expressed as $\mathrm{mg}$ of gallic acid equivalents/g of extract (GAEs).

\subsection{Antioxidant activity}

Reagents. BHA (2-tert-butyl-4-methoxyphenol), TBHQ (tert-butylhydroquinone) and $\alpha$-tocopherol were purchased from Sigma (St. Louis, MO, USA). 2,2-Diphenyl-1-picrylhydrazyl (DPPH) was obtained from Alfa Aesar. All other chemicals were obtained from Sigma Chemical Co. (St. Louis, USA). Methanol was obtained from Pronalab (Lisboa, Portugal). Water was treated in a Mili-Q water purification system (TGI Pure Water Systems, USA).

Reducing power assay. The reducing power was determined according to a described procedure (Oyaizu, 1986; Ferreira et al., 2007). Various concentrations of sample extracts $(2.5 \mathrm{~mL})$ were mixed with $2.5 \mathrm{~mL}$ of $200 \mathrm{mmol} / \mathrm{L}$ sodium phosphate buffer $(\mathrm{pH} 6.6)$ and $2.5 \mathrm{~mL}$ of $1 \%$ potassium ferricyanide. The mixture was incubated at $50{ }^{\circ} \mathrm{C}$ for $20 \mathrm{~min}$. After incubation $2.5 \mathrm{~mL}$ of $10 \%$ trichloroacetic acid (w/v) were added and then the mixture was centrifuged at $1000 \mathrm{rpm}$ in a refrigerated centrifuge (Centorion K24OR-2003), for $8 \mathrm{~min}$. The upper layer $(5 \mathrm{~mL})$ was mixed with $5 \mathrm{~mL}$ of deionised water and $1 \mathrm{~mL}$ of $0.1 \%$ of ferric chloride, and the absorbance was measured spectrophotometrically at $700 \mathrm{~nm}$. The extract concentration providing 0.5 of absorbance $\left(\mathrm{EC}_{50}\right)$ was calculated from the graph of absorbance registered at $700 \mathrm{~nm}$ against the correspondent extract concentration. BHA and $\alpha$-tocopherol were used as reference compounds.

Scavenging effect assay. The capacity to scavenge the 2,2-diphenyl-1picrylhydrazyl (DPPH) free radical was monitored according to a method reported before (Hatano et al., 1988). Various concentrations of sample extracts $(0.3 \mathrm{~mL})$ were mixed with $2.7 \mathrm{~mL}$ of methanolic solution containing DPPH radicals $\left(6 \times 10^{-5} \mathrm{~mol} / \mathrm{L}\right)$. The mixture was shaken vigorously and left to stand in the dark until stable absorption values were obtained. The reduction of the DPPH radical was measured by monitoring continuously the decrease of absorption at $517 \mathrm{~nm}$. DPPH scavenging effect was calculated as percentage of DPPH discolouration using the equation: \% scavenging effect $=\left[\left(A_{\mathrm{DPPH}}-A_{\mathrm{S}}\right) / A_{\mathrm{DPPH}}\right] \times 100$, where $A_{\mathrm{S}}$ is the absorbance of the solution when the sample extract has been added at a particular level and $A_{\mathrm{DPPH}}$ is the absorbance of the DPPH solution. The extract concentration providing $25 \%$ inhibition $\left(\mathrm{EC}_{25}\right)$ was calculated from the graph of scavenging effect percentage against extract concentration. BHA and $\alpha$-tocopherol were used as reference compounds.

$\beta$-Carotene linoleate model system. The antioxidant activity of walnut kernel extracts was evaluated according to a described procedure (Mi-Yae et al., 2003). $\beta$-Carotene solution was prepared by dissolving $2 \mathrm{mg}$ of $\beta$ carotene in $10 \mathrm{~mL}$ of chloroform. Two millilitres of this solution were placed in a $100 \mathrm{~mL}$ round-bottom flask. After chloroform removal, at $40^{\circ} \mathrm{C}$ under vacuum, $40 \mathrm{mg}$ of linoleic acid, $400 \mathrm{mg}$ of Tween 80 emulsifier, and $100 \mathrm{~mL}$ of distilled water were added to the flask under vigorous shaking. Aliquots $(4.8 \mathrm{~mL})$ of this emulsion were transferred into different test tubes containing $0.2 \mathrm{~mL}$ of different concentrations of walnut extracts. The tubes were shaken and incubated at $50^{\circ} \mathrm{C}$ in a water bath. As soon as the emulsion was added to each tube, the zero time absorbance at $470 \mathrm{~nm}$ was measured. Absorbance readings were then recorded until the control sample had changed colour. A blank assay, devoid of $\beta$-carotene, was prepared for background subtraction. Antioxidant activity was calculated using the following equation: Antioxidant activity $=(\beta$-carotene content after $2 \mathrm{~h}$ of assay/initial $\beta$-carotene content) $\times 100$. The assays were carried out in triplicate and the results were expressed as mean values \pm standard deviations. The extract concentration providing $25 \%$ antioxidant activity $\left(\mathrm{EC}_{25}\right)$ was calculated from the graph of antioxidant percentage against extract concentration. TBHQ was used as reference compound.

\subsection{Antimicrobial activity}

Reagents. Ampicillin and cycloheximide were of the highest available quality, and purchased from Merck (Darmstadt, Germany). Water was treated in a Mili-Q water purification system (TGI Pure Water Systems, USA).

Microorganisms and culture conditions. Microorganisms CECT were obtained from the Spanish type culture collection (CECT) of Valencia University, while microorganisms ESA were clinically isolated strains identified in Microbiology Laboratory of Escola Superior Agrária de Bragança. Gram $+($ B. cereus CECT 148, B. subtilis CECT 498 and $S$. aureus ESA 7 isolated from pus) and gram $-($ E. coli CECT 101, $P$. aeruginosa CECT 108 and $K$. pneumoniae ESA 8 isolated from urine) bacteria, and fungi (C. albicans CECT 1394 and C. neoformans ESA 3 isolated from vaginal fluid) were used to screen antimicrobial activity of the three walnut cultivars. Microorganisms were cultured aerobically at $37^{\circ} \mathrm{C}$ (Scientific 222 oven model, 2003) in nutrient agar medium for bacteria, and at $30^{\circ} \mathrm{C}$ (Scientific 222 oven model, 2003) in sabouraud dextrose agar medium for fungi.

Test assays for antimicrobial activity. The screening of antibacterial activities against gram + and gram - bacteria and fungi and the determination of the minimal inhibitory concentration (MIC) were achieved by an adaptation of the agar streak dilution method based on radial diffusion (Hawkey and Lewis, 1994; Ferreira et al., 2004; Sousa et al., 2006). Suspensions of the microorganism were prepared to contain approximately $10^{8} \mathrm{cfu} / \mathrm{mL}$, and the plates containing agar medium were inoculated $(100 \mu \mathrm{L}$; spread on the surface). Each sample $(50 \mu \mathrm{L})$ was placed in a hole (3 $\mathrm{mm}$ depth, $4 \mathrm{~mm}$ diameter) made in the centre of the agar. Under the same conditions, different solutions of ampicillin (antibacterial) and cycloheximide (antifungal) were used as standards. The MIC was considered to be the lowest concentration of the tested sample able to inhibit the growth of bacteria after $24 \mathrm{~h}$ and fungi after $48 \mathrm{~h}$. The diameters of the inhibition zones corresponding to the MICs were measured using a ruler, with an accuracy of $0.5 \mathrm{~mm}$. Each inhibition zone diameter was measured three times (three different plates) and the average was considered. A control using only inoculation was also carried out.

\section{Results and discussion}

\subsection{Chemical analysis and fatty acid composition}

The proximate composition of the different analyzed walnut varieties is shown in Table 1 . Fat was the highest constitute in all samples, ranging from $68.83 \%$ in $c v$. Marbot to $72.14 \%$ in $c v$. Franquette. Moisture and ash presented the lower values, with mean values of $4 \%$. Moisture content was higher in $c v$. Mellanaise $(4.50 \%)$ and lower in $c v$. Lara $(3.85 \%)$, while ash content was higher in $c v$. Mellanaise $(4.26 \%)$ and lower in $c v$. Parisienne $(3.31 \%)$. The results indicate that walnut consumption conduce to a high input level of energetic value, ranged from $711 \mathrm{kcal}$ in $c v$. Mayette and $727.4 \mathrm{kcal}$ in $c v$. Franquette (Table 1). If the obtained results were compared with the ones previously obtained for fruits collected in the same cultivars and in the same orchard by Amaral et al. (2003), some differences can be observed namely ash, fat content (both higher on the present work) and carbohydrates (lower in the present work). Its differences could be attributed to the harvesting year and environmental condition, with different temperatures, rainfall and light, which can influence the chemical composition of fruits (Parcerisa et al., 1995). 
Table 1

Proximate chemical composition (grams per $100 \mathrm{~g}$ of fresh weight) of walnut cultivars grown in Portugal (mean \pm SD)

\begin{tabular}{llllll}
\hline Cultivar & Moisture & Crude protein & Total fat & Carbohydrates & Ash \\
\hline Franquette & $4.07 \pm 0.03$ & $15.65 \pm 0.22$ & $72.14 \pm 0.27$ & $3.88 \pm 0.10$ & $7.23 \pm 0.02$ \\
Lara & $3.85 \pm 0.05$ & $14.38 \pm 0.27$ & $70.59 \pm 0.59$ & $7.16 \pm 0.36$ & $7.03 \pm 0.01$ \\
Marbot & $4.10 \pm 0.14$ & $18.03 \pm 0.29$ & $68.83 \pm 2.00$ & $4.86 \pm 2.3$ & $7.18 \pm 0.13$ \\
Mayette & $3.99 \pm 0.06$ & $16.33 \pm 0.02$ & $71.89 \pm 1.08$ & $3.75 \pm 1.49$ & 71.0 \\
Mellanaise & $4.50 \pm 0.22$ & $15.42 \pm 0.14$ & $69.75 \pm 0.37$ & $6.10+0.31$ & $7.04 \pm 0.45$ \\
Parisienne & $4.28 \pm 0.21$ & $15.82 \pm 0.12$ & $71.51 \pm 0.04$ & $5.09 \pm 0.59$ & $7.26 \pm 0.02$ \\
\hline
\end{tabular}

Mean values and standard deviations of the fatty acid composition for the six walnut varieties are shown in Table 2. The fatty acids profile is constituted by 19 fatty acids, and all the studied varieties presented similar profile in constitution with some variations among fatty acids (Table 2). Linoleic acid was the most abundant one in all varieties ranging from $55.51 \%$ in $c v$. Franquette to $60.30 \%$ in $c v$. Lara. Oleic acid was the second in order of importance ranging from $14.92 \%$ ( $c v$. Franquette) to $20.22 \%$ ( $c v$. Lara) followed by linolenic acid, from $13.2 \%$ ( $c v$. Parisienne) to $17.61 \%$ ( $c v$. Mayette). In the remaining fatty acids only palmitic (5.95-6.61\%) and stearic acids $(2.70-3.07 \%)$ showed considerable amounts. In general terms, the obtained results were in agreement with the observed in Portuguese samples (Amaral et al., 2003) and other geographical origin such us Italy (Ruggeri et al., 1998), Canada (Li et al., 2007), and New Zealand (Zwarts et al., 1999).

Fatty acid analysis allowed the estimation of the different nutritional fractions: saturated fatty acids (SFA), monounsaturated fatty acids (MUFA) and polyunsaturated fatty acids (PUFA). PUFA (due to the high content of linoleic acid) were the main component of total fat extracted from the studied cultivars, representing values higher than $69.55 \%$ of total fat. MUFA were present in percentages ranging from $15.16 \%(c v$. Lara) to $20.53 \%$ ( $c v$. Franquette). SFA content were the minor group, with lower than $10 \%$ (Table 2). Walnut fat is mostly unsaturated, and unsaturated fatty acids have been associated with beneficial effects on serum lipids (Feldman, 2002). Walnuts have high amounts of omega -6 and omega -3 PUFA, which are essential dietary fatty acids. Epidemiological and clinical studies suggest that omega-3 PUFA may have a significant role in the prevention of coronary heart disease and showed that the inclusion of walnut consumption in the diet had a significant protective benefit with respect to fatal and nonfatal coronary heart diseases events (Davis et al., 2007).

The study of phenolic content present in the different walnut cultivars aqueous extracts (Table 3 ) revealed values between $58.78 \mathrm{mg}$ GAES/g in $c v$. Lara and $95.06 \mathrm{mg}$ GAES/g in $c v$. Mayette. Comparing our results with the results obtained by Kornsteiner et al. (2006), that registered $1025 \mathrm{mg} \mathrm{GAE} / 100 \mathrm{~g}$, we concluded that all the extracts prepared by us showed high amounts in a ratio from 3.6

Table 2

Fatty acid composition (percent) of oil extracted from analyzed walnut samples (mean \pm SD)

\begin{tabular}{|c|c|c|c|c|c|c|}
\hline & \multicolumn{6}{|l|}{$\underline{\text { Cultivar }}$} \\
\hline & Franquette & Lara & Marbot & Mayette & Mellanaise & Parisienne \\
\hline $\mathrm{C}_{14: 0}$ & $0.03 \pm 0.00$ & $0.04+0.00$ & $0.03 \pm 0.00$ & $0.02+0.00$ & $0.02+0.00$ & $0.03+0.00$ \\
\hline $\mathrm{C}_{15: 0}$ & $0.01 \pm 0.00$ & $0.02+0.00$ & $0.01 \pm 0.00$ & $0.01+0.00$ & $0.01+0.00$ & $0.02+0.00$ \\
\hline $\mathrm{C}_{16: 0}$ & $6.61 \pm 0.08$ & $6.28+0.01$ & $6.35 \pm 0.01$ & $5.95+0.05$ & $6.31+0.04$ & $6.16+0.05$ \\
\hline $\mathrm{C}_{16: 1}$ & $0.10 \pm 0.00$ & $0.06+0.00$ & $0.07 \pm 0.00$ & $0.07+0.00$ & $0.07+0.00$ & $0.08+0.00$ \\
\hline $\mathrm{C}_{17: 0}$ & $0.04 \pm 0.00$ & $0.04+0.00$ & $0.05 \pm 0.00$ & $0.04+0.00$ & $0.05+0.00$ & $0.04+0.00$ \\
\hline $\mathrm{C}_{17: 1} c-10$ & $0.03 \pm 0.00$ & $0.02+0.00$ & $0.02 \pm 0.00$ & $0.02+0.00$ & $0.03+0.00$ & $0.03+0.00$ \\
\hline $\mathrm{C}_{18: 0}$ & $3.07 \pm 0.02$ & $2.80+0.03$ & $2.78 \pm 0.01$ & $2.70+0.03$ & $2.80+0.02$ & $2.90+0.01$ \\
\hline $\mathrm{C}_{18: 1} \mathrm{n} 9 \mathrm{c}+\mathrm{t}$ & $20.22 \pm 0.02$ & $14.92+0.11$ & $16.34 \pm 0.11$ & $16.08+0.08$ & $17.09+0.16$ & $19.50+0.12$ \\
\hline $\mathrm{C}_{18: 2 \mathrm{n} 6 \mathrm{c}}$ & $55.51 \pm 0.03$ & $60.30+0.34$ & $59.66 \pm 0.25$ & $57.14+0.33$ & $58.75+0.34$ & $57.68+0.37$ \\
\hline $\mathrm{C}_{18: 3} \mathrm{n} 3$ & $14.01 \pm 0.00$ & $15.20+0.17$ & $14.33 \pm 0.12$ & $17.61+0.15$ & $14.51+0.11$ & $13.20+0.18$ \\
\hline $\mathrm{C}_{20: 0}$ & $0.11 \pm 0.00$ & $0.10+0.00$ & $0.09 \pm 0.00$ & $0.10+0.00$ & $0.09+0.00$ & $0.10+0.00$ \\
\hline $\mathrm{C}_{20: 1} c-11$ & $0.18 \pm 0.00$ & $0.16+0.01$ & $0.18 \pm 0.00$ & $0.18+0.00$ & $0.17+0.00$ & $0.18+0.00$ \\
\hline $\mathrm{C}_{20: 2} c-11.14$ & $0.02 \pm 0.00$ & $0.03+0.00$ & $0.03 \pm 0.00$ & $0.03+0.00$ & $0.02+0.00$ & $0.02+0.00$ \\
\hline $\mathrm{C}_{20: 4} \mathrm{n} 6$ & $0.01 \pm 0.00$ & $0.00+0.00$ & $0.00 \pm 0.00$ & $0.00+0.00$ & $0.00+0.00$ & $0.00+0.00$ \\
\hline $\mathrm{C}_{20: 3} \mathrm{n} 3+\mathrm{C}_{21: 0}$ & $0.01 \pm 0.00$ & $0.01+0.00$ & $0.01+0.00$ & $0.01+0.00$ & $0.01+0.00$ & $0.01+0.00$ \\
\hline $\mathrm{C}_{22: 0}$ & $0.03 \pm 0.00$ & $0.02+0.00$ & $0.03+0.00$ & $0.03+0.00$ & $0.03+0.00$ & $0.03+0.00$ \\
\hline $\mathrm{C}_{22: 1} \mathrm{n} 9$ & $0.01 \pm 0.00$ & $0.01+0.00$ & $0.01+0.00$ & $0.01+0.00$ & $0.01+0.00$ & $0.01+0.00$ \\
\hline $\mathrm{C}_{23: 0}$ & $0.01 \pm 0.00$ & $0.01+0.00$ & $0.01+0.00$ & $0.00+0.00$ & $0.01+0.00$ & $0.01+0.00$ \\
\hline $\mathrm{C}_{24: 0}$ & $0.01 \pm 0.00$ & $0.00+0.00$ & $0.01+0.00$ & $0.01+0.00$ & $0.01+0.00$ & $0.01+0.00$ \\
\hline SFA & $9.91 \pm 0.10$ & $9.30 \pm 0.04$ & $9.35 \pm 0.02$ & $8.86 \pm 0.08$ & $9.33 \pm 0.06$ & $9.29 \pm 0.06$ \\
\hline MUFA & $20.53 \pm 0.02$ & $15.16 \pm 0.12$ & $16.62 \pm 0.11$ & $16.35 \pm 0.08$ & $17.37 \pm 0.16$ & $19.79 \pm 0.12$ \\
\hline PUFA & $69.55 \pm 0.03$ & $75.54 \pm 0.51$ & $74.03 \pm 0.37$ & $74.79 \pm 0.48$ & $73.29 \pm 0.45$ & $70.92 \pm 0.55$ \\
\hline
\end{tabular}


Table 3

Total phenolic contents $\left(\mathrm{mg}\right.$ GAES/g) and $\mathrm{EC}_{50}$ values $(\mathrm{mg} / \mathrm{mL})$ of walnut aqueous extracts

\begin{tabular}{llllr}
\hline Cultivar & Total phenols contents & Reducing power $\left(\mathrm{EC}_{50}\right)$ & ${\text { DPPH }\left(\mathrm{EC}_{50}\right)}$ \\
\hline Franquette & $78.56 \pm 0.01$ & 0.19 & 0.15 & 0.22 \\
Lara & $58.78 \pm 0.00$ & 0.26 & 0.20 & 3.63 \\
Marbot & $60.83 \pm 0.01$ & 0.23 & 0.16 & 3.96 \\
Mayette & $95.06 \pm 0.03$ & 0.17 & 0.22 & 3.09 \\
Mellanaise & $75.87 \pm 0.01$ & 0.25 & 0.16 & 3.02 \\
Parisienne & $91.09 \pm 0.02$ & 0.16 & 1.56 \\
\hline
\end{tabular}

to 5.8 folds more. However, those authors also observed that walnut fruits showed the highest total phenolic contents when 10 nuts (almonds, Brazil nuts, cashews, hazelnuts, macadamias, peanuts, pecans, pines, pistachios and walnuts) were studied. Probably, the differences in the results could be explained by the different extraction methodologies. In the present study water at boiling temperature was use as extraction solvent whereas Kornsteiner et al. (2006) extracted the phenolic fraction with a solution of $75 \%$ acetone and $25 \%$ of $526 \mu \mathrm{mol} / \mathrm{L}$ sodium metabisulfite.

\subsection{Antioxidant activity}

In the present work, the antioxidant potential of walnut kernel samples was measured by three different assays: reducing power, scavenging activity on DPPH radicals and lipid peroxidation inhibition by $\beta$-carotene linoleate system.

Reducing power assay results are showed in Fig. 1. A concentration-dependent activity is observed. In this assay, the yellow colour of the test solution changes to various shades of green and blue, depending on the reducing power of each compound. The presence of reducers (i.e. antioxidants) causes the conversion of the $\mathrm{Fe}^{3+} /$ ferricyanide complex used in this method to the ferrous form. Therefore, by measuring the formation of Perl's Prussian blue at $700 \mathrm{~nm}$, we can monitor the $\mathrm{Fe}^{2+}$ concentration; a higher absorbance at $700 \mathrm{~nm}$ indicates a higher reducing power. Wal- nut's kernel showed high reducing power, even at concentrations below $1 \mathrm{mg} / \mathrm{mL}$, being even more potent than BHA $\left(A_{700}=0.12\right.$ at $\left.3.6 \mathrm{mg} / \mathrm{mL}\right)$ and $\alpha$-tocopherol ( $A_{700}=0.13$ at $\left.8.6 \mathrm{mg} / \mathrm{mL}\right)$ standards. All the six cultivars showed similar results, especially to concentrations below $0.1 \mathrm{mg} / \mathrm{mL}$. Cultivar Parisienne presented the best results (lowest $\mathrm{EC}_{50}$ values), while $c v$. Lara presented the worse results (highest $\mathrm{EC}_{50}$ values for reducing power, Table 3 ).

Scavenging activity on DPPH radicals assay provides basic information about the antiradical activity of extracts, and is expressed as the ratio percentage of sample absorbance decrease and the absorbance of DPPH solution in the absence of extract at $517 \mathrm{~nm}$. In the present work, aqueous walnut lyophilized extracts of all the six walnut cultivars revealed a strong concentration-dependent antioxidant activity (Fig. 2). The scavenging activity on DPPH radicals were very high at low extract concentrations. At an extract concentration of $0.5 \mathrm{mg} / \mathrm{mL}$, the activity ranged from $90.2 \%$, for $c v$. Lara extracts, to $92.6 \%$ for $c v$. Parisenne (Fig. 2). The obtained results are much better that the ones achieved for BHA $(96.0 \%$ at $3.6 \mathrm{mg} / \mathrm{mL})$ and $\alpha$ tocopherol $(95.0 \%$ at $8.6 \mathrm{mg} / \mathrm{mL})$ standards. The results were similar for all cultivars, being $c v$. Parisienne the one with lower $\mathrm{EC}_{50}$ value $(0.16 \mathrm{mg} / \mathrm{mL})$, and $c v$. Lara the one with the highest $\mathrm{EC}_{50}$ value $(0.26 \mathrm{mg} / \mathrm{mL})$ (Table 3$)$.

The antioxidant activity of walnut lyophilized extracts measured by the bleaching of $\beta$-carotene is shown in Fig. 3. The linoleic acid free radical attacks the highly unsaturated $\beta$-carotene models. The presence of different

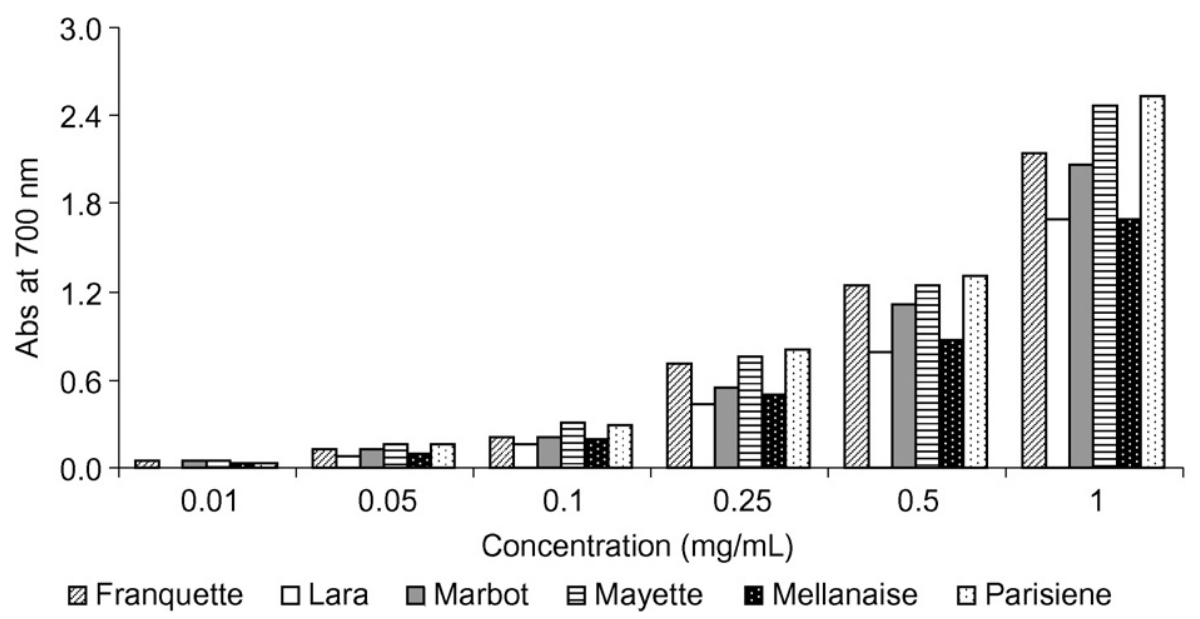

Fig. 1. Reducing power values of different walnut cultivars aqueous extracts. Each value is expressed as mean \pm standard deviation. 


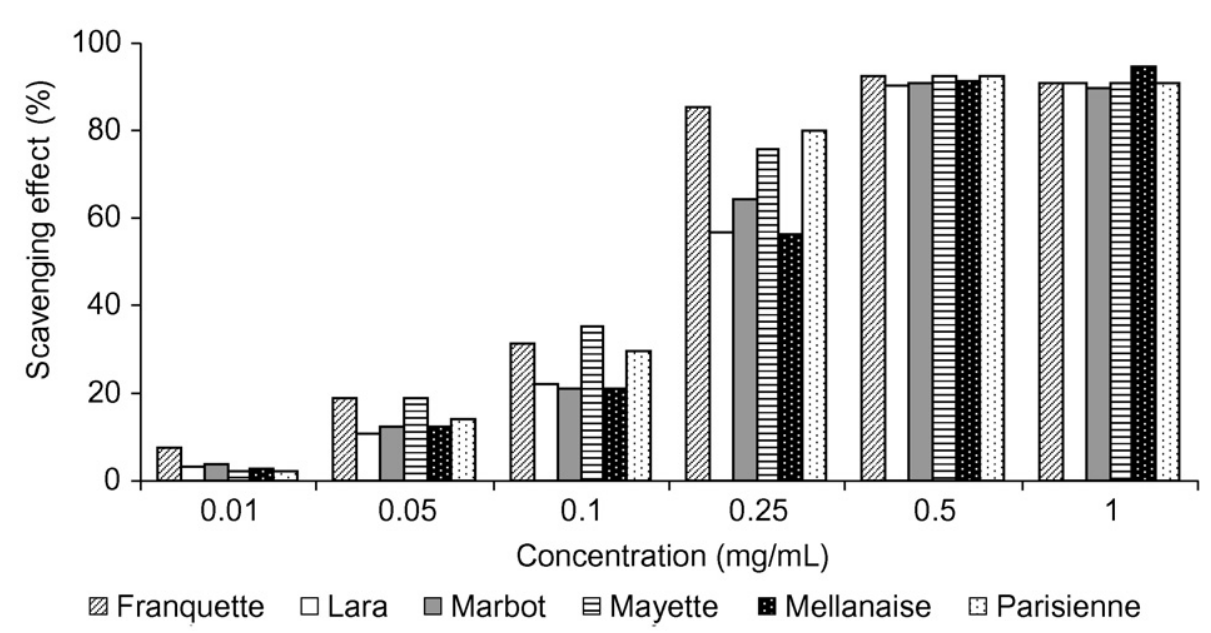

Fig. 2. Scavenging effect on DPPH of different walnut cultivars aqueous extracts. Each value is expressed as mean \pm standard deviation.

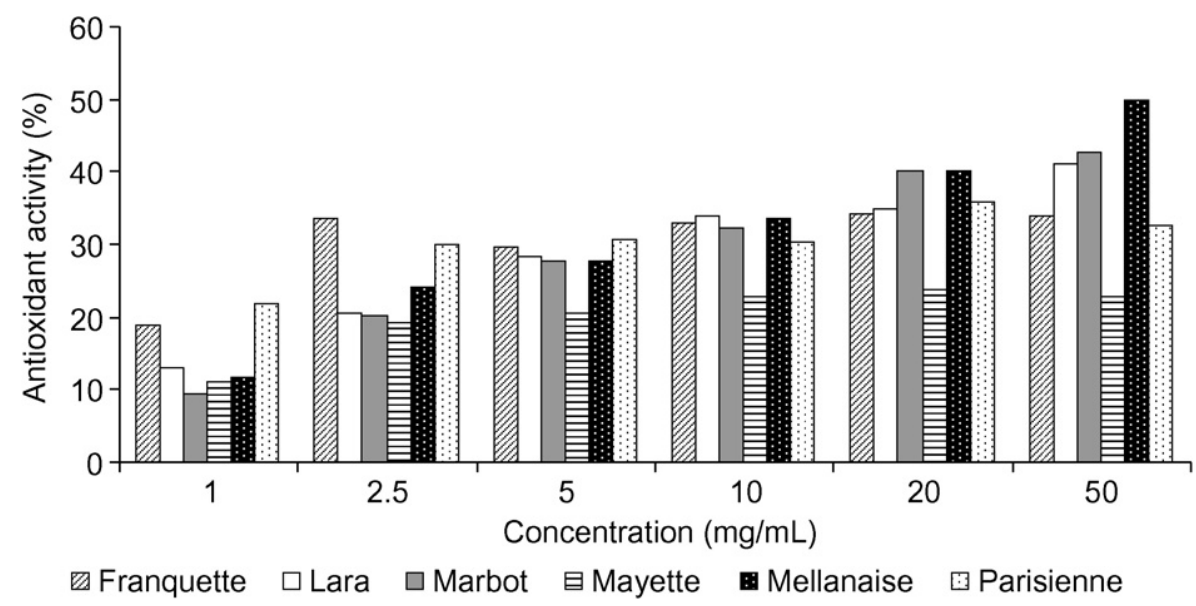

Fig. 3. Antioxidant activity $(\%)$ by $\beta$-carotene bleaching method of different walnut cultivars aqueous extracts. Each value is expressed as mean \pm standard deviation.

antioxidants can hinder the extent of $\beta$-carotene bleaching by neutralizing the linoleate-free radical and other free radicals formed in the system (Jayaprakasha et al., 2001). Accordingly, the absorbance decreased rapidly in samples without antioxidant, whereas in the presence of an antioxidant, they retained their colour, and thus absorbance, for a longer time. Again, concentration-dependent activity is observed. The best results were obtained with $c v$. Parisienne, while $c v$. Mayette presented the worse results. In this assay, $c v$. Parisienne presented the lowest $\mathrm{EC}_{25}$ value (Table 3). TBHQ standard showed higher antioxidant activity than the tested samples $(82.2 \%$ at $2 \mathrm{mg} / \mathrm{mL})$.

Antioxidant activity of walnut kernels and walnut oils has already been evaluated by DPPH method (Espín et al., 2000). Nevertheless, the authors attribute the antioxidant capacity of walnut oils to the presence of tocopherols (Savage et al., 1999; Espín et al., 2000). The $\mathrm{EC}_{50}$ values of nuts (both walnut and heartnut) obtained from the DPPH assay were correlated significantly and inversely with the total tocopherol contents, indicating that tocopherols are the principal components responsible for the antioxidant effect. Espín et al. (2000) also suggested that the radical scavenging capacity of the lipid fraction of the different plant oils including walnut oil was mainly due to the content of all the tocopherols. Those authors used as extraction solvents methanol and ethanol (Espín et al., 2000), hexane (Li et al., 2006, 2007), ethyl acetate and different combinations of solvents (hexane/ethyl acetate/methanol), solvents that allowed the extraction of tocopherols.

The present work reports for the first time the use of water as solvent extraction, and therefore we attributed the high antioxidant activity to the high amount of total phenols (Table 3). Aqueous extracts of other matrices with high fat content, such as table olives (Pereira et al., 2006), stoned table olives (Sousa et al., 2008) and hazelnuts (Oliveira et al., in press), also showed relevant antioxidant activity. In this work, when we correlate the total phenols content and antioxidant activity of walnut aqueous extracts, in a general way an increase of total phenols content was associated with a decrease of $\mathrm{EC}_{50}$ values. A sig- 
nificantly negative linear correlation was established between the total phenols content and $\mathrm{EC}_{50}$ reducing power values (determination coefficients $0.743 ; p=0.027$ ) and between total phenols content and $\mathrm{EC}_{25}$ for $\beta$-carotene bleaching system, when the $c v$. Mayette was excluded (determination coefficients $0.858 ; p=0.024$ ). However for $\mathrm{DPPH}$ scavenging effect $\mathrm{EC}_{50}$ values no significantly correlation was established (determination coefficients 0.547; $p=0.093$ ). The negative linear correlation proves that the sample with highest phenols content shows higher antioxidant activities ( $c v$. Parisienne). On walnut kernels several polyphenols have been identified, namely chlorogenic acid, caffeic acid, $p$-coumaric acid, ferulic acid, and sinapic acid (hydroxycinnamic acids) and ellagic acid and syringic acid (hydroxybenzoic acids) as well as syringaldehyde (hydroxybenzoic aldehyde) and juglone (quinone) (Colaric et al., 2005).

\subsection{Antimicrobial activity}

Table 4 shows the antimicrobial screening of six walnut aqueous extracts (from $c v$. Franquette, Lara, Marbot, Mayette, Mellanaise and Parisienne) against B. cereus, B. subtilis, S. aureus, E. coli, $P$. aeruginosa, $K$. pneumoniae, $C$. albicans and $C$. neoformans. The minimal inhibitory concentration (MIC) values for the tested bacteria and fungi were determined as an evaluation of the antimicrobial activity of the samples.

All the tested extracts revealed antimicrobial activity. However the action of each walnut extract variety was different according the tested microorganism.

Gram positive bacteria (B. cereus, B. subtilis, S. aureus) were inhibited by $c v$. Lara aqueous extract at very low concentrations, presenting MICs of $1 \mathrm{mg} / \mathrm{mL}$ for B. cereus, and $0.1 \mathrm{mg} / \mathrm{mL}$ for $B$. subtilis and $S$. aureus. $S$. aureus was also inhibited for $c v$. Franquette but at higher extract concentration $(100 \mathrm{mg} / \mathrm{mL})$ (Table 4).
Gram negative bacteria ( $P$. aeruginosa, E. coli and $K$. Pneumoniae) were also sensible for some walnut extracts. $c v$. Lara inhibited the growth of $K$ pneumoniae (MIC of $100 \mathrm{mg} / \mathrm{mL}$ ), $c v$. Mayette inhibited the development of $P$. aeruginosa and $E$. coli with MICs of 50 and $10 \mathrm{mg} / \mathrm{mL}$, respectively, and $c v$. Mellanaise inhibited the growth of E. coli and K. pneumoniae at concentration of $100 \mathrm{mg} / \mathrm{mL}$.

All the walnut varieties exhibited antifungi activity against the tested species (C. albicans and C. neoformans). C. albicans was susceptible to five walnut varieties, only being resistant to $c v$. Mellanaise extract. The higher inhibition was observed with $c v$. Lara extract (MIC of $1 \mathrm{mg} / \mathrm{mL}$ ). On the other hand C. neoformans was resistant to $c v$. Mellanaise extract at the tested concentrations (maximum of $100 \mathrm{mg} / \mathrm{mL}$ ) and was very sensitive to $c v$. Franquette extract (MIC of $0.1 \mathrm{mg} / \mathrm{mL}$ ). As expected, the standards ampiciline (antibacterial) and cycloheximide (antifungal) presented lower MICs than the walnut extracts. Usually, pure active compounds reveal more activity than crude extracts.

Similarly to the results observed in walnut leaves (Pereira et al., 2007), $c v$. Lara fruit extracts proved to be the most promissory cultivar. The extracts of this cultivar inhibited five of the eight microorganisms tested, and was effective against gram positive and gram negative bacteria and fungi, which increase their potentiality.

Some authors demonstrated that phenolic compounds possess antimicrobial activity (Rauha et al., 2000; Puupponen-Pimiä et al., 2001; Proestos et al., 2005; Pereira et al., $2006,2007)$ that varied in a dependent manner with a total phenolic content of the tested extracts (Vaquero et al., 2007). But in this study no phenolic concentration dependence was observed. The $c v$. Lara extract, with lower total phenols (58.78 mg GAES/g) was the most effective against microorganisms. This situation could be related with the nature of the fenolic fraction that constitutes the extracts. In fact, studies with pure phenolic compounds showed distinct antimicrobial activity according to the studied compounds (Vaquero et al., 2007).

Table 4

Antimicrobial activity $[\mathrm{MIC}(\mathrm{mg} / \mathrm{mL})]$ of walnut aqueous extracts

\begin{tabular}{|c|c|c|c|c|c|c|c|c|}
\hline & \multicolumn{6}{|l|}{ Cultivar } & \multicolumn{2}{|l|}{ Standards } \\
\hline & Franquette & Lara & Marbot & Mayette & Mellanaise & $\overline{\text { Parisienne }}$ & Ampicillin & Cycloheximide \\
\hline B. cereus & $100(-)$ & $1(++)$ & $100(-)$ & $100(-)$ & $100(-)$ & $100(-)$ & $0.00313(++++)$ & NT \\
\hline B. subtilis & $100(-)$ & $0.1(+++)$ & $100(-)$ & $100(-)$ & $100(-)$ & $100(-)$ & $0.0125(++++)$ & NT \\
\hline S. aureus & $100(+++)$ & $0.1(+++)$ & $100(-)$ & $100(-)$ & $100(-)$ & $100(-)$ & $0.00625(++++)$ & NT \\
\hline P. aeruginosa & $100(-)$ & $100(-)$ & $100(-)$ & $50(++++)$ & $100(-)$ & $100(-)$ & $0.00625(++++)$ & NT \\
\hline E. coli & $100(-)$ & $100(-)$ & $100(-)$ & $10(+++)$ & $100(+++)$ & $100(-)$ & $0.00625(++++)$ & NT \\
\hline K. pneumoniae & $100(-)$ & $100(+++)$ & $100(-)$ & $100(-)$ & $100(++++)$ & $100(-)$ & $0.00625(++++)$ & NT \\
\hline C. albicans & $10(++++)$ & $1(++++)$ & $10(+)$ & $50(+++)$ & $100(-)$ & $50(+++)$ & NT & $0.0125(++)$ \\
\hline C. neoformans & $0.1(++++)$ & $100(-)$ & $10(+++)$ & $50(+)$ & $10(+)$ & $50(++)$ & NT & $0.00625(++++)$ \\
\hline
\end{tabular}

No antimicrobial activity $(-)$, inhibition zone $<1 \mathrm{~mm}$. Slight antimicrobial activity $(+)$, inhibition zone $2-3 \mathrm{~mm}$. Moderate antimicrobial activity $(++)$, inhibition zone 4-5 mm. High antimicrobial activity $(+++)$, inhibition zone $6-9 \mathrm{~mm}$. Strong antimicrobial activity $(++++)$, inhibition zone $>9 \mathrm{~mm}$. Standard deviation $\pm 0.5 \mathrm{~mm}$. NT - not tested. 
In some cases, walnut extracts, with higher MICs, showed similar antimicrobial activity to walnut leaf extracts for the same cultivars (Pereira et al., 2007) and other plant extracts like hazel leaves (Oliveira et al., 2007), hazelnut fruits (Oliveira et al., in press) and olive fruits (Pereira et al., 2006; Sousa et al., 2006). Walnut fruit extracts proved to have antifungi action against $C$. albicans and C. neoformans, two important yeasts that cause human diseases, and which was not observed in the referred matrices (walnut leaves, hazel leaves, hazelnut fruits and table olives).

\section{Conflict of interest statement}

The authors declare that there are no conflicts of interest.

\section{Acknowledgments}

The authors are grateful to INTERREG III A Program, Project PIREFI for financial support of this work.

\section{References}

Amaral, J.S., Casal, S., Pereira, J., Seabra, R., Oliveira, B., 2003. Determination of sterol and fatty acid compositions, oxidative stability, and nutritional value of six walnut (Juglans regia L.) cultivars grown in Portugal. J. Agric. Food Chem. 51, 7698-7702.

Amaral, J.S., Cunha, S., Alves, M.R., Pereira, J.A., Seabra, R.M. Oliveira, M.B.P.P., 2004. Triacylglycerols composition of walnut (Juglans regia L.) cultivars: characterization by HPLC/ELSD and chemometrics. J. Agric. Food Chem. 52, 7664-7969.

Amaral, J.S., Alves, M., Seabra, R., Oliveira, B., 2005. Vitamin E composition of walnuts (Juglans regia L.): a 3-year comparative study of different cultivars. J. Agric. Food Chem. 53, 5467-5472.

Anderson, K.J., Teuber, S.S., Gobeille, A., Cremin, P., Waterhouse, A.L., Steinberg, F.M., 2001. Walnut polyphenolics inhibit in vitro human plasma and LDL oxidation. J. Nutr. 131, 2837-2842.

AOAC, 1995. Official Methods of Analysis, sixteenth ed. Association of Official Analytical Chemists, Arlington, VA.

Blomhoff, R., Carlsen, M.H., Andersen, L.F., Jacobs Jr., D.R., 2006. Health benefits of nuts: potential role of antioxidants. Brit. J. Nutr. 96, S52-S60.

Colaric, M., Veberic, R., Solar, A., Hudina, M., Stampar, F., 2005. Phenolic acids, syringaldehyde, and juglone in fruits of different cultivars of Juglans regia L.. J. Agric. Food Chem. 53, 6390-6396.

Cowan, M.M., 1999. Plant products as antimicrobial agents. Clin. Microbiol. Rev. 12, 564-582.

Davis, L., Stonehouse, W., Loots, D.T., Mukuddem-Petersen, J., van der Westhuizen, F., Hanekom, S.J., Jerling, J.C., 2007. The effects of high walnut and cashew nut diets on the antioxidant status of subjects with metabolic syndrome. Eur. J. Nutr. 46, 155-164.

Decreto-Lei no. 167/2004 de 7 de Julho.

Espín, J.C., Soler-Rivas, C., Wichers, H.J., 2000. Characterization of the total free radical scavenger capacity of vegetable oils and oil fractions using 2,2-diphenyl-1-picrylhydrazyl radical. J. Agric. Food Chem. 48, 648-656.

Feldman, E.B., 2002. The scientific evidence for a beneficial health relationship between walnuts and coronary heart disease. J. Nutr. 132, 1062S-1101S.

Fernández, M., Garcia, M., Sáenz, M., 1996. Antibacterial activity of the phenolic acid fraction of Scrophularia frutescens and Scrophularia sambucifolia. J. Ethnopharmacol. 53, 11-14.
Ferreira, I.C.F.R., Calhelha, R.C., Estevinho, L.M., Queiroz, M.-J.R.P., 2004. Screening of antimicrobial activity of diarylamines in the 2,3,5trimethylbenzo $[b]$ thiophene series: a structure-activity evaluation study. Bioorg. Med. Chem. Lett. 14, 5831-5833.

Ferreira, I.C.F.R., Barros, L., Soares, M.E., Bastos, M.L., Pereira, J.A., 2007. Antioxidant activity and total phenolic contents of Olea europaea L. leaves sprayed with different copper formulations. Food Chem. 103, 188-195.

Fukuda, T., Ito, H., Yoshida, T., 2003. Antioxidant polyphenols from walnuts (Juglans regia L.). Phytochemistry 63, 795-801.

Hatano, T., Kagawa, H., Yasuhara, T., Okuda, T., 1988. Two new flavonoids and other constituents in licorice root: their relative astringency and scavenging effects. Chem. Pharm. Bull. 36, 2090-2097.

Hawkey, P.M., Lewis, D.A., 1994. Medical Bacteriology - A Practical Approach. Oxford University, UK, pp. 181-194.

Jayaprakasha, G.K., Singh, R.P., Sakariah, K.K., 2001. Antioxidant activity of grape seed (Vitis vinifera) extracts on peroxidation models in vitro. Food Chem. 73, 285-290.

Koksak, A., Artik, N., Simsek, A., Gunes, N., 2006. Nutrient composition of hazelnut (Corylus avellana L.) varieties cultivated in Turkey. Food Chem. 99, 509-515.

Kornsteiner, M., Wagner, K.-H., Elmadfa, I., 2006. Tocopherol and total phenolics in 10 different nut types. Food Chem. 98, 381-387.

Li, L., Tsao, R., Yang, R., Liu, C.M., Zhu, H.H., Young, J.C., 2006. Polyphenolic profiles and antioxidant activities of heartnut (Juglans ailanthifolia var. cordiformis) and Persian walnut (Juglans regia L.). J. Agric. Food Chem. 54, 8033-8040.

Li, L., Tsao, R., Yang, R., Kramer, J.K.G., Hernandez, M., 2007. Fatty acid profiles, tocopherol contents, and antioxidant activities of heartnut (Juglans ailanthiofolia var. cordiformis) and Persian walnut (Juglans regia L.). J. Agric. Food Chem. 55, 1164-1169.

Mi-Yae, S., Tae-Hun, K., Nak-Ju, S., 2003. Antioxidants and free radical scavenging activity of Phellinus baumii (Phellinus of Hymenochaetaceae) extracts. Food Chem. 82, 593-597.

Oliveira, I., Sousa, A., Valentão, P., Andrade, P., Ferreira, I.C.F.R., Ferreres, F., Bento, A., Seabra, R., Estevinho, L., Pereira, J.A., 2007. Hazel (Corylus avellana L.) leaves as source of antimicrobial and antioxidative compounds. Food Chem. 105, 1018-1025.

Oliveira, I., Sousa, A., Sá Morais, J., Ferreira, I.C.F.R., Bento, A., Estevinho, L., Pereira, J.A., in press. Chemical composition, and antioxidant and antimicrobial activities of three hazelnut (Corylus avellana L.) cultivars. Food Chem. Toxicol. 46, 1801-1807.

Oyaizu, M., 1986. Studies on products of browning reactions: antioxidative activities of products of browning reaction prepared from glucosamine. Jap. J. Nut. 44, 307-315.

Parcerisa, J., Rafecas, M., Castellote, A., Codony, R., Farran, A., Garcia, J., Gonzalez, C., Lopez, A., Romero, A., Boatella, J., 1995. Influence of variety and geographical origin on the lipid fraction of hazelnut (Corylus avellana L.) from Spain: (III) oli stability, tocopherol content and some mineral contents $(\mathrm{Mn}, \mathrm{Fe}, \mathrm{Cu})$. Food Chem. 53, 71-74.

Pereira, J.A., Pereira, A.P.G., Ferreira, I.C.F.R., Valentão, P., Andrade, P.B., Seabra, R., Estevinho, L., Bento, A., 2006. Table olives from Portugal: phenolic compounds, antioxidant potential and antimicrobial activity. J. Agric. Food Chem. 54, 8425-8431.

Pereira, J.A., Oliveira, I., Sousa, A., Valentão, P., Andrade, P.B., Ferreira, I.C.F.R., Ferreres, F., Bento, A., Seabra, R., Estevinho, L., 2007. Walnut (Juglans regia L.) leaves: phenolic compounds, antimicrobial activity and antioxidant potential of different cultivars. Food Chem. Toxicol. 45, 2287-2295.

Proestos, C., Chorianopoulos, N., Nychas, G.-J.E., Komaitis, M., 2005. RP-HPLC analysis of the phenolic compounds of plant extracts. Investigation of their antioxidant capacity and antimicrobial activity. J. Agric. Food Chem. 53, 1190-1195.

Puupponen-Pimiä, R., Nohynek, L., Meier, C., Kähkönen, M., Heinonen, M., Hopia, A., Oksman-Caldentey, K.-M., 2001. Antimicrobial properties of phenolic compounds from berries. J. Appl. Microbiol. 90, 494-507. 
Ramadan, M., Moersel, J., 2006. Screening of the antiradical action of vegetable oils. J. Food Compos. Anal. 19, 838-842.

Rauha, J.-P., Remes, S., Heinonen, M., Hopia, A., Kähkönen, M., Kujala, T., Pihlaja, K., Vuorela, H., Vuorela, P., 2000. Antimicrobial effects of Finnish plant extracts containing flavonoids and other phenolic compounds. Int. J. Food Microbiol. 56, 3-12.

Reiter, R.J., Manchester, L.C., Dun-xian Tan, M.D., 2005. Melatonin in walnuts: influence on levels of melatonin and total antioxidant capacity of blood. Nutrition 21, 920-924.

Ruggeri, S., Cappelloni, L., Gambelli, S., Carnovale, E., 1998. Chemical composition and nutritive value of nuts grown in Italy. Ital. J. Food Sci. 3, 243-252.

Savage, G.P., Dutta, P.C., McNeil, D.L., 1999. Fatty acid and tocopherol contents and oxidative stability of walnut oils. J. Am. Oil Chem. Soc. 76, 1059-1063.

Singleton, V.L., Rossi Jr., J.A., 1965. Colorimetric of total phenolics with phosphomolybdic-phosphotungstic acid reagents. Am. J. Enol. Viticult. 16, 144-158.
Sousa, A., Ferreira, I.C.F.R., Calhelha, R., Andrade, P.B., Valentão, P., Seabra, R., Estevinho, L., Bento, A., Pereira, J.A., 2006. Phenolics and antimicrobial activity of traditional stoned table olives "alcaparra". Bioorg. Med. Chem. 14, 8533-8538.

Sousa, A., Ferreira, I.C.F.R., Barros, L., Bento, A., Pereira, J.A., 2008. Antioxidant potential of traditional stoned table olives "Alcaparras": influence of the solvent and temperature extraction conditions. LWT Food Sci. Technol. 41, 739-745.

Tapsell, L., Gillen, L.J., Patch, C.S., Batterham, M., Owen, A., Baré, M., Kennedy, M., 2004. Including walnuts in a low-fat/modified-fat diet improves HDL cholesterol-to-total cholesterol ratios in patients with type 2 diabetes. Diabetes Care 27, 2777-2783.

Vaquero, M.J.R., Alberto, M.R., Nadra, M.C.M., 2007. Antibacterial effect of phenolic compounds from different wines. Food Control 18, 93-101.

Zwarts, L., Savage, G.P., McNeil, D.L., 1999. Fatty acid content of New Zealand-grown walnuts (Juglans regia L.). Int. J. Food Sci. Nutr. 50, 189-194. 